Revue

Revue de l'histoire des religions

del'histoire des religions

L'Ordre chrétien médiéval entre le droit et la foi

\title{
Loi ancienne, loi nouvelle et normes chrétiennes dans la théologie scolastique du XIII ${ }^{\mathrm{e}}$ siècle
}

Ancient Law, New Law, and Christian Norms in $13^{\text {th }}$ Century Scholastic Theology

\section{Elsa Marmursztejn}

\section{OpenEdition}

Journals

Édition électronique

URL : https://journals.openedition.org/rhr/7822

DOI : 10.4000/rhr.7822

ISSN : 2105-2573

Éditeur

Armand Colin

Édition imprimée

Date de publication : 1 décembre 2011

Pagination : 509-539

ISBN : 978-2200-92722-6

ISSN : 0035-1423

\section{Référence électronique}

Elsa Marmursztejn, « Loi ancienne, loi nouvelle et normes chrétiennes dans la théologie scolastique du xIII ${ }^{e}$ siècle », Revue de l'histoire des religions [En ligne], 4 | 2011, mis en ligne le 01 décembre 2014, consulté le 21 septembre 2021. URL : http://journals.openedition.org/rhr/7822 ; DOI : https://doi.org/ $10.4000 /$ rhr.7822 


\section{ELSA MARMURSZTEJN}

Université de Reims

(CERHIC: Centre de recherche en histoire culturelle)

Institut universitaire de France

\section{Loi ancienne, loi nouvelle et normes chrétiennes dans la théologie scolastique du XIII ${ }^{\mathrm{e}}$ siècle}

L'article vise à montrer que la tension originaire entre le christianisme et la Loi, illustrée dans le premier art chrétien par le motif de la Traditio legis, a été assumée par les théologiens du XIII siècle non seulement dans leur conception dialectique des rapports entre Ancien et Nouveau Testament, mais aussi dans la construction scolastique de normes chrétiennes sur la base de préceptes vétérotestamentaires (comme ceux du sabbat ou de la dîme). S'y révèlent, de façon générale, le rôle spécifique des maîtres dans "l'accomplissement" de la Loi inauguré par le Christ; de façon particulière, l'interaction forte entre théologie et droit canonique, observée ici dans la déconstruction et la refondation théologique du précepte de la dîme.

\section{Ancient Law, New Law, and Christian Norms in $13^{\text {th }}$ Century Scholastic Theology}

This paper aims at showing that the original tension between Christianity and the Law, represented by the Traditio legis motif in early Christian art, is assumed by the thirteenth century theologians not only in their dialectic conception of the relationships between Old et New Testaments, but also in the scholastic working out of Christian norms grounded on Old-Testament precepts such as those imposing Sabbath observance or the paying of tithes. In a general way, they show the specific role of the masters in "fulfilling" the Law, as initiated by Christ; in a more particular way, they also show the strong interweaving of theology and canon law which can be observed in the theological deconstruction and recasting of the obligation of paying tithes. 
Issu du judaïsme conçu comme religion de la Loi, le christianisme entretient avec le droit des rapports originaires et complexes. Comme l'a observé Marcel Simon dans son ouvrage classique, l'antilégalisme initial, fondé sur la distinction paulinienne entre la foi et la Loi, et néanmoins tempéré par la distinction entre des prescriptions cérémonielles jugées obsolètes et des préceptes moraux confirmés par le Christ, avait fait place à un «nouveau nomisme $»^{1}$ : le Christ n'était pas venu abolir, mais accomplir la Loi (Matthieu 5, 17); l'Ancien Testament, indispensable à la compréhension du message chrétien, restait le fondement de la foi; le Verus Israel recueillait l'héritage dont les juifs s'étaient révélés indignes. Le christianisme se présentait donc moins comme une rupture que comme une espèce nouvelle du même genre ${ }^{2}$ : Paul se dit soumis à la «loi du Christ» (1 Corinthiens, 9, 21); les Pères évoquent la «loi de l'Évangile»³. La tension entre la grâce et la Loi se résolvait par des alliances de mots - «loi de grâce», «loi parfaite de liberté $»^{4}$ - qui traduisaient la substitution de la loi du Christ à celle de Moïse et exprimaient la différence spécifique de la loi évangélique.

Dans le premier art chrétien, les représentations de la Traditio legis témoignent précisément de cette substitution de la «loi nouvelle» à la Loi ancienne. Le don fait par le Christ à Pierre, nouveau Moïse, du rouleau de la Nouvelle alliance, constitue l'un des motifs iconographiques les plus populaires et les plus représentatifs de la période comprise entre le $\mathrm{IV}^{\mathrm{e}}$ et le $\mathrm{VI}^{\mathrm{e}}$ siècle, avant que s'impose le motif de la remise des clés ${ }^{5}$. La signification de l'image est souvent explicitée par l'inscription Dominus legem dat. À Sainte-Constance de Rome (milieu du IV ${ }^{\text {e }}$ siècle), les niches de l'axe transversal sont ainsi ornées de mosaïques représentant le don de la loi: dans celle de droite, Dieu donne la loi à Moïse; dans celle de gauche, le Christ donne la loi à Pierre sous la forme d'un rouleau portant

1. Marcel Simon, Verus Israel. Étude sur les relations entre chrétiens et Juifs dans l'Empire romain, 135-425, Paris, De Boccard, 1948, p. 100.

2. Rémi Brague, La Loi de Dieu. Histoire philosophique d'une alliance, Paris, Gallimard, 2005, p. 252-253.

3. Ibid., p. 115 et 253 .

4. Cf. Marcel Simon, op. cit., p. 100-101.

5. Ibid., p. 100; R. Brague, op. cit., p. 253. 
l'inscription Dominus legem dat ${ }^{6}$. Celle-ci figure également sur le rouleau que le Christ, debout sur un globe bleu, remet à Pierre dans le baptistère napolitain de Saint-Jean (fin du IV ${ }^{\mathrm{e}}$-début du V $\mathrm{V}^{\mathrm{e}}$ siècle) ${ }^{7}$. Les sarcophages ont cependant constitué le support privilégié de la représentation de la Traditio legis, qui figure communément au centre des frises sculptées dans les ateliers romains entre 360 et 410 environ ${ }^{8}$. C'est le cas du célèbre sarcophage de Probus sur lequel le Christ, tenant la croix dans la main droite et le rouleau dans la main gauche, remet la loi à Pierre ${ }^{9}$; de celui du préfet Iunius Bassus mort en 359, dont la composition triangulaire met en valeur la centralité du Christ entouré des apôtres Pierre et Paul ${ }^{10}$; mais c'est aussi le cas des sarcophages de Ravenne ${ }^{11}$ ou de Saint-Ambroise de Milan, où le Christ debout donne la loi en présence des apôtres ${ }^{12}$. Les discussions sur l'interprétation du motif de la Traditio legis ont notamment mis en relief, dans les années soixante, la question de la primauté de Pierre en tant que destinataire de la loi, et celle des liens entre la remise de la loi par le Christ et la remise de la foi (traditio ou redditio Symboli) au catéchumène dans l'Église des $\mathrm{III}^{\mathrm{e}}-\mathrm{V}^{\mathrm{e}}$ siècles ${ }^{13}$. Les interprétations récentes se caractérisent par la mise à distance de la lecture «impériale» et de la lecture «doctrinale» du thème de la Traditio legis. Le premier art chrétien aurait moins transposé les thématiques impériales ${ }^{14}$ qu'il n'aurait figuré les principes justifiant l'autonomie d'une Église fondée sur la sacralité des Évangiles, la divinité ou la majesté du Christ ${ }^{15}$. D'autre part, le choix du motif ne procédait pas de sa seule valeur symbolique, mais des avantages

6. Yves-Marie Congar, «Le thème du "don de la Loi" dans l'art paléochrétien », Nouvelle Revue Théologique, 84-2 (1962), p. 916; André Grabar, Le premier art chrétien (200-395), Paris, Gallimard, 1966, p. 192, n 207.

7. Yves-Marie Congar, loc. cit., p. 917.

8. Bas Snelders, «The Traditio legis on Early Christian Sarcophagi», Antiquité tardive, 13 (2005), p. 330.

9. André Grabar, op. cit., p. 257, fig. 285.

10. Dictionnaire d'Archéologie Chrétienne et de Liturgie [DACL] 2, 609 et fig. 1460; Yves-Marie Congar, loc. cit., p. 918.

11. DACL 6, 649 et fig. 4871 ; Yves-Marie Congar, loc. cit., p. 918.

12. André Grabar, op. cit., p. 263, n 293 (vue d'ensemble) et p. 261, n 290 (détail).

13. Yves-Marie Congar, op. cit., p. 915-933.

14. Soit des motifs liés à l'idéologie et au cérémonial impérial: position; port du rouleau qui, dans la main de l'empereur, figure le pouvoir suprême du juge; formule legem dat qui renvoie à l'acte souverain du législateur, etc.

15. Anne-Orange Poilpré, Maiestas Domini: une image de l'Église en Occident, $V^{e}-I X^{e}$ siècle, Paris, Cerf, 2005, p. 71. 
esthétiques et pratiques d'une composition pyramidale, propre à figurer harmonieusement au centre d'une frise de sarcophage, et dont l'effet de symétrie était éventuellement renforcé par des détails iconographiques ajoutés sur commande (montagne et fleuves du paradis, agneaux, palmiers) ${ }^{16}$. Ces hypothèses affinent la compréhension du contexte et confirment l'importance du motif, sans remettre fondamentalement en cause la signification, confortée par l'inscription Dominus legem dat, de la Traditio legis.

Le fait que, sur la plupart des frises de sarcophages qui représentent le Christ donnant la loi à Pierre, ce motif soit mêlé à celui du Christ enseignant, un livre à la main, et à celui de la mission donnée aux apôtres ${ }^{17}$, débouche en outre sur la double question du destinataire et du contenu de la loi. Pour Yves Congar, l'incontestable primauté de Pierre dans les représentations du don de la loi tient au fait qu'il représente «tout l'apostolat du sacerdoce et tous les fidèles», soit «l'Église en son unité » ${ }^{18}$. Dans les siècles suivants, l'attribution des clés à Pierre et du livre de la loi à Paul suggère la spécialisation des deux apôtres : la «plénitude d'autorité» de Pierre lui vaut de détenir les clés; la "plénitude de sagesse» de Paul est figurée par le livre unique qu'il porte ${ }^{19}$. Quant au contenu de la loi donnée par le Christ législateur, il était indéterminé. Aussi représentait-il adéquatement la «loi nouvelle» de l'Évangile: il ne s'agissait pas d'une loi particulière, mais du christianisme lui-même ${ }^{20}$, conçu comme secunda legislatio ${ }^{21}$. Dans la littérature patristique, la représentation du Christ législateur voisine avec l'identification du Christ à la loi. Vers 150, le philosophe et martyr Justin identifie le Christ à la «loi éternelle» et à «l'alliance nouvelle ${ }^{22}$. Au IV ${ }^{\mathrm{e}}$ siècle, Lactance le désigne comme «loi vivante», combinant l'image évangélique du Christ professeur au Temple «envoyé par le Père» (Jean 7, 14 sq.)

16. Bas Snelders, loc. cit., p. 333.

17. Yves-Marie Congar, loc. cit., p. 918-919; Bas Snelders, loc. cit., p. 330.

18. Yves-Marie Congar, loc. cit., p. 921.

19. Sur la question des rapports entre Pierre et Paul comme figures de l'autorité et de la science, je me permets de renvoyer à Elsa Marmursztejn, "Autorité et vérité dans les relations entre la papauté et les docteurs parisiens au XIII ${ }^{\mathrm{e}}$ siècle», dans Gianluca Potestà éd., Autorität und Wahrheit. Kirchliche Vorstellungen, Normen und Verfahren (13.-15. Jahrhundert), Schriften des Historischen Kollegs, Kolloquien, Band 84, Munich, Oldenbourg Verlag, 2011, p. 21-44.

20. Yves-Marie Congar, loc. cit., p. 929.

21. Origène, cité par Yves-Marie Congar, loc. cit., p. 930.

22. Rémi Brague, op. cit., p. 253. 
et la figure de la «Loi vivante» issue de la philosophie politique grecque: «Dieu envoya son ambassadeur et messager pour instruire l'humanité mortelle des préceptes de sa justice [...]. Car, puisqu'il n'y avait pas de justice sur terre, il envoya un professeur, en quelque sorte une Loi vivante, pour fonder un nouveau nom et un nouveau temple $»^{23}$. Enfin, la «loi nouvelle» est identifiée à la croix par l'auteur inconnu, contemporain de Tertullien, du De montibus Sina et Sion: «La Loi des chrétiens est la sainte croix du Christ, fils du Dieu vivant $»^{24}$. L'identification du Christ à la loi et de la loi à la croix révèle très clairement un paradoxe capital: la «loi nouvelle» ne se concevait pas comme un ensemble de commandements, mais comme un «nouveau régime de salut $»^{25}$.

Donnée par le Christ, la «loi nouvelle» apparaît, dans son indétermination et son universalité mêmes, à la fois comme un contrepoint à la somme des préceptes particuliers formant la Loi ancienne, et comme le fruit ou l'aboutissement de cette «loi pédagogue ${ }^{26}$, dont les prescriptions constituaient les degrés d'une échelle historique et didactique conduisant au Christ comme «vrai maître» de la «doctrine de vérité». On s'intéressera ici à la façon dont la tension fondamentale entre le discours sur la Loi et la construction des normes chrétiennes s'est exprimée dans la théologie du XIII ${ }^{\mathrm{e}}$ siècle. On postulera que cette tension s'est accrue au XIII ${ }^{\text {e }}$ siècle: la convergence méthodique et culturelle de la théologie et du droit, perceptible dès l'émergence et la distinction disciplinaire des deux sciences vers le milieu du $\mathrm{XII}^{\mathrm{e}}$ siècle, se traduit alors par une commune aspiration à la production de normes rationnelles et par le partage de cadres d'énonciation et de références, dans le monde culturel et institutionnel neuf de la scolastique et des universités. Indéterminée, la «loi de grâce» et de «liberté» donnée par le Christ débouche sur des prescriptions théologiques qui combinent l'efficacité de la raison et celle du droit.

23. Lactance, Divinae Institutiones, IV, 25, éd. Pierre Monat, Paris, Cerf (SC 377), 1992, p. 204; Ernst Kantorowicz, Les Deux corps du roi, Paris, Gallimard, Quarto, 2000, p. 756-757.

24. «Lex christianorum crux est sancta Christi filii Dei vivi, dicente aeque propheta: Lex tua in medio ventris mei [Ps. 39, 9]» (cité par Yves-Marie Congar, loc. cit., p. 930).

25. Rémi Brague, op. cit., p. 254.

26. Suivant l'expression systématiquement commentée de l'Épître aux Galates, 3, 24. 


\section{CONCEPTIONS SCOLASTIQUES SUR LES RAPPORTS ENTRE ANCIENNE ET NOUVELLE LOI}

Que le Christ soit venu «accomplir, et non détruire» la Loi (Matthieu 5, 17) impliquait de réfléchir aux modalités d'un tel accomplissement en définissant notamment les formes de continuité entre les deux testaments ${ }^{27}$. On ne reviendra pas ici sur le mouvement général de l'exégèse, ni sur l'évolution, soulignée en particulier par Beryl Smalley ${ }^{28}$, que dessine au XIII ${ }^{\mathrm{e}}$ siècle la réflexion nouvelle sur la validité du sens littéral des préceptes de l'ancienne Loi. On s'attachera en revanche aux termes dans lesquels les maîtres du XIII ${ }^{\text {e }}$ siècle ont exprimé l'infrangibilité du lien entre les deux testaments, inscrivant le travail théologique dans un cadre proprement «légal», et à la façon dont ils ont mis l'accent sur la fonction didactique de la loi, érigeant le don de la loi (par Dieu, par le Christ) en modèle de l'enseignement théologique. Dans le vaste dossier des textes scolastiques produits au XIII ${ }^{\text {e }}$ siècle sur ce sujet (commentaires sur l'Épître aux Galates, questions et traités sur la Loi ou sur la cessation des legalia), on relèvera donc les métaphores mobilisées pour illustrer les liens entre ancienne et nouvelle Loi, soit - par ordre croissant d'importance dans le dossier - la métaphore du développement naturel, celle du Christ architecte, celle du Christ médecin, celle de la «loi pédagogue» et du Christ maitre, que tous les auteurs ont développée à divers degrés, en relation avec les différents âges de la vie et avec le modèle d'un enseignement humain progressif et différencié.

Dans le registre des métaphores naturelles, le traité De legalibus d'Olivi (c. 1290) révèle l'emploi de deux figures particulières. À l'argument de la différence spécifique entre les deux lois - la Loi nouvelle se définissant par «la grâce, la vertu, la charité et la vie éternelle accessible par la grâce du Christ», en contrepoint à la Loi

27. Le thème n'est pas neuf au XIII ${ }^{\text {e }}$ siècle; sur «l'unité des deux testaments», on verra Henri de Lubac, Exégèse médiévale. Les quatre sens de l'Écriture, Paris, Aubier, t. 1-1, 1959, p. 305-363.

28. Beryl Smalley, The Study of the Bible in the Middle Ages, University of Notre Dame Press, 1964 [3 édition, 1978]; Ead., «William of Auvergne, John of la Rochelle, and St. Thomas Aquinas on the Old Law», dans St. Thomas Aquinas, 1274-1974, Toronto, Pontifical Institute of Medieval Studies, 1974, vol. 1, p. 10-71, repr. dans Studies in Medieval Thought and Learning from Abelard to Wyclif, Londres, Hambledon Press, 1981, p. 121-183. 
ancienne définie par «la crainte servile et les biens temporels $»^{29}-$, Olivi répond que «la loi nouvelle et la loi ancienne ne diffèrent pas dans l'absolu par l'espèce, ni ne sont totalement deux lois », mais que «de même que le fruit et la branche de l'arbre constituent l'arbre entier et parfait avec sa racine, de même la loi nouvelle est contenue dans l'ancienne comme la poule dans l'œuf $»^{30}$. Si l'on dépassait la distinction de la loi écrite et de la grâce ou celle de la lettre et de l'esprit par la comparaison entre le statut de l'Ancien Testament et celui du Nouveau dans leur ensemble, il apparaissait qu'ils différaient «comme la poule et l'œuf, comme l'arbre et la semence dont il était sorti» et «comme ce qui est implicite, imparfait et matériel diffère de ce qui est explicite, parfait et pleinement formé $»^{31}$. C'est de façon plus spécifique et plus ample que la riche métaphore de la semence et de la germination ${ }^{32}$ avait été développée par Robert Grosseteste dans son traité De cessatione legalium (vers 1230-1235). Répondant à l'argument selon lequel le Christ était venu accomplir et non détruire la Loi, Grosseteste distinguait les choses dont l'être était permanent et dont relevaient les moralia, des choses dont l'être était transitoire et dont relevaient les cerimonialia, «comme la loi de la circoncision et du sabbat $»^{33}$. On disait que le Christ avait accompli les unes et les autres, en donnant aux moralia «la permanence et la vie de la charité » et en mettant fin aux cerimonialia «par la génération d'un sens et d'une œuvre spirituels $»^{34}$. La métaphore de la germination illustrait efficacement la production de ce sens spirituel: "L'être de la semence (esse seminis) est que par la germination il passe dans la chose qui doit être procréée naturellement à partir de la semence. C'est pourquoi il accomplit vraiment et ne détruit pas la semence, celui qui la fait germer en temps opportun et la fait passer dans une autre forme, plus parfaite. Par exemple: c'est accomplir et non détruire la

29. Pierre de Jean Olivi, De legalibus, Napoli, Bib. Naz., XII A 23, fol. 2ra.

30. Ibid., fol. $6 \mathrm{rb}$.

31. Ibid., fol. 6va.

32. La métaphore est employée par Pierre le Chantre dans la Summa Abel, recueil de distinctiones du dernier quart du $\mathrm{XII}^{\mathrm{e}}$ siècle, pour montrer que l'antériorité de la Loi n'implique pas sa supériorité: "Sicut prius est spica quam granum et utilius est granum spica, ita iudei prius fuerunt quam christiani et tamen christiani legem habent meliorem» (cf. Gilbert Dahan, «L'article Iudei de la Summa Abel de Pierre le Chantre», Revue des Études augustiniennes, 27 (1981), p. 106 et 117).

33. Robert Grosseteste, De cessatione legalium, Particula prima, X, § 28, éd. Richard C. Dales et Edward B. King, Oxford University Press, 1986, p. 65.

34. Ibid., p. 66. 
semence de l'arbre ou la semence du blé, que de la faire mourir dans la terre où elle pourrit, passer par germination dans l'arbre ou l'épi de blé, et [lui faire] perdre ainsi la forme et l'être de la semence. Il accomplit la semence et ne la détruit pas, celui qui conduit la semence au non-être ( $a d$ non esse) de cette façon-là», à la différence de «celui qui remet la semence dans le cellier pour l'utiliser pendant plusieurs années et ne permet pas qu'en mourant, elle germe $»^{35}$.

La métaphore de la construction a également servi à illustrer l'idée d'accomplissement de la Loi. Seul Robert Grosseteste en donne une version développée, dans le traité De cessatione legalium où l'on trouve, parmi les raisons censées justifier la continuation de l'observance des legalia, l'argument suivant: «Si quelqu'un pose un toit et détruit aussitôt ce qu'il a achevé, il parachève l'édifice et détruit ce qu'il a accompli. Or le Christ a accompli et non détruit la loi [...]. Quel sage achève un édifice et le détruit sitôt achevé ? S'il décide si vite de le détruire, dans quel but l'achève-t-il? Puisque donc le Fils est la plus grande sagesse, il n'a pas détruit la loi qu'il a lui-même accomplie $»^{36}$. Grosseteste répond que le Christ «a entièrement accompli les sacrements des deux testaments, en sorte qu'il a joint, en tant que pierre angulaire, les deux murs de l'édifice du culte divin; car tout le rite du culte qu'il faut rendre à Dieu est, du début du genre humain à la consommation du monde, comme un édifice unique. Parce que toutefois un édifice est quelque chose de transitoire, ses parties doivent se succéder, et c'est pourquoi il incombait au Christ, en tant que véritable architecte et que fondement angulaire (verum architectum et angulare fundamentum $)^{37}$, de joindre le mur du culte de Dieu selon les rites de la loi de charité au mur du culte de Dieu selon les rites cérémoniels $»^{38}$. Un autre texte, édité sous le titre de Templum Dei, avait déjà révélé le goût de Grosseteste pour la métaphore architecturale. La singularité de ce petit ouvrage de théologie pratique et pastorale, composé entre 1220 et 1230 à destination des simples prêtres, tenait essentiellement à l'usage didactique de listes, de diagrammes et de schémas insérés dans le texte. Le théologien y enseignait la façon d'édifier et de

35. Ibid., § 27, p. 65.

36. Ibid., Particula prima, §13-14, p. 12-13.

37. Le Christ est pierre angulaire et architecte, comme il est loi et législateur.

38. Robert Grosseteste, De cessatione legalium, Particula prima, VIII, § 31, éd. cit., p. 67. 
préserver le temple de Dieu: les vertus de tempérance, de force et de prudence formaient respectivement les fondations, les murs et le toit du temple corporel; les vertus théologales (foi, espérance, charité) formaient les fondations, les murs et le toit du temple spirituel. Par ailleurs, l'idée que la Loi constituait un «mur intermédiaire, destiné à éviter que l'édification continue des bonnes mœurs ne soit rompue», apparaît incidemment dans une question de la Somme du maître séculier Henri de Gand ${ }^{39}$. Elle y fait surtout écho à la métaphore de l'échelle qui constitue, dans le De cessatione legalium de Robert Grosseteste, le moyen de sortir du «puits du péché»: les sacramenta legalia et mandata veteris legis positiva avaient été insérés comme autant de degrés intermédiaires entre les commandements de la loi naturelle; ils devaient être ôtés afin que la vertu et la puissance du Christ libérateur fussent plus manifestes et que l'amour de celui qu'il avait libéré fût plus ardent ${ }^{40}$.

La métaphore thérapeutique est envisagée dans la même perspective historique dans la somme de théologie franciscaine dite d'Alexandre de Halès et dans l'Expositio de Robert Grosseteste sur l'Épitre aux Galates, ainsi que dans la Somme de théologie de Thomas d'Aquin: l'avènement du Christ coïncidait avec le moment où le «malade», ayant pris conscience de son état, recourait volontairement au «médecin» dont il attendait le remède. Suivant Alexandre de Halès, Dieu avait donné la Loi non crudeliter, sed misericorditer, à titre de consilium medicinae ${ }^{41}$. Parce que l'homme présumait de ses forces, la Loi l'avait rendu capable de comprendre sa faiblesse et la nécessité de recourir à l'aide de la grâce. L'ordo curationis exigeait qu'il prît d'abord conscience de sa maladie, puis qu'il désirât le remède. Ayant fait l'expérience de son ignorance sous le régime de la loi naturelle, il avait ainsi recherché le conseil qui lui avait été fourni par la loi de Moïse, sous le régime de laquelle il avait éprouvé l'impuissance qui lui avait fait rechercher l'aide «en quoi consiste la grâce du Christ, que prêche l'Évangile». ${ }^{42}$ Pour Robert Grosseteste, le moment où «le

39. Henri de Gand, Summa quaestionum ordinarium, Reprint of the 1520 Edition, The Franciscan Institute St. Bonaventure, New York-Louvain-Paderborn, Nauwelaerts, F. Schöningh, 1953, t. 1, art. 8, q. 5, fol. 67v.

40. Robert Grosseteste, De cessatione legalium, Particula prima, VIII, § 9-11, éd. cit., p. 43-44.

41. Alexandre de Halès, Summa theologica, pars II, inquisitio 4, tr. 1, q. 10, c. 1, Ed. Coll. S. Bonaventurae, Quarrachi, 1948, t. 4, p. 873.

42. Ibid., c. 2 , ad $1^{\text {um }}$, p. 878. 
genre humain a fait l'expérience de ce qu'il ne pouvait être justifié par la loi naturelle au moyen de ses propres forces, ni ensuite par la loi écrite ni par les prophètes [...] et où, comprenant qu'il était malade et faible, il a recouru au médecin», correspond à celui de la plenitudo temporis évoquée dans l'Épître aux Galates $(4,4)$ et qui pouvait s'interpréter comme la consummatio infirmitatis ${ }^{43}$. Dans son commentaire du même verset de l'Épître aux Galates, Thomas d'Aquin répétait que «parce que le médecin devait venir, il fallait qu'avant son avènement les hommes soient convaincus de leur maladie, et quant à leur manque de science sous la loi naturelle, et quant à leur manque de force sous la loi écrite. Et par conséquent il a fallu que l'avènement du Christ soit précédé de l'une et de l'autre, c'est-à-dire de la loi naturelle et de la loi écrite ${ }^{44}$. Chez Henri de Gand, la métaphore apparaît, dans une perspective quelque peu différente, dans la réfutation de l'argument selon lequel le sage (Dieu) ne modifiait pas ce qu'il avait établi (la Loi): «De même que le médecin a ordonné au convalescent un régime qu'il change lorsque sa santé se confirme, de même Dieu a établi l'Ancien Testament en tant qu'il était adapté (congruum) au peuple ancien, auquel le Nouveau ne pouvait convenir, et qui convint ensuite au peuple nouveau [...]. De même que l'art de la médecine ne change pas, [...] mais que les préceptes changent parce que la santé est changeante, de même la divine providence, alors qu'elle est ellemême absolument immuable, porte cependant secours à une créature changeante, et ordonne et interdit des choses différentes selon la diversité des maladies $»^{45}$.

La nécessité d'adapter la Loi à ses récipiendaires humains est également au cœur des commentaires théologiques sur la métaphore paulinienne de la «loi pédagogue»(Galates 3, 24-25). La puérilité paradoxale du «peuple ancien $»^{46}$ forme le corollaire de cette métaphore. L'opposition commune entre le populus parvulus destinataire de l'ancienne Loi et le populus adultus apte à recevoir

43. Robert Grosseteste, Expositio in epistolam sancti Pauli ad Galatas, éd. James McEvoy, Turnhout, Brepols, 1995, p. 99.

44. Thomas d'Aquin, Commentaire de l'Épître aux Galates, c. 4, leçon 2, v. 4-5, trad. Jean-Eric Stroobant de Saint-Eloy, Paris, Cerf, 2008, p. 157.

45. Henri de Gand, Summa quaestionum ordinarium, éd. cit., art. 9, q. 1, fol. 70v.

46. «Ipsa huiusmodi puerilitas vetustas spiritualis est» (Guillaume d'Auvergne, De legibus, cap. 1, dans Guilielmi Alverni episcopi Parisiensis opera omnia, t. 1, Rouen, F. Hotot, 1674, p. 23b). 
la Loi nouvelle a donné lieu à divers développements. Robert Grosseteste et Alexandre de Halès ont ainsi rapporté la succession des trois âges de l'humanité à celle des trois états de la loi. À l'humanité dans l'enfance, laissée aux mouvements et au gouvernement de la nature, succède l'adolescence déréglée, dotée d'un pédagogue et d'une loi de crainte, puis l'âge parfait, régi par la loi d'amour et de libertét ${ }^{47}$. La distinction ainsi établie par Robert Grosseteste entre l'infantia et l'adolescentia fait place chez Alexandre de Halès à une distinction entre l'infantia (avant la Loi) et la pueritia (sous la Loi). Seule la iuventus (à l'époque de la grâce) était «susceptible de la perfection de la doctrine, et c'est pourquoi la loi de l'Évangile devait alors être donnée, qui est la perfection de la discipline $»^{48}$.

La métaphore de l'enfance du peuple de l'ancienne Loi est filée au moyen de détails concrets sur l'alimentation des jeunes enfants. Guillaume d'Auvergne explique la multitude des commandements de la Loi ancienne par l'incapacité du peuple ancien à recevoir des préceptes généraux: Dieu avait décrété qu'il deva it être instruit par des commandements particuliers, à l'instar du petit enfant «qu'il faut nourrir de morceaux de pain [...] plutôt que de pains entiers $»^{49}$. Pour illustrer l'idée que l'ancienne Loi n'était pas mauvaise, mais qu'elle avait cessé d'être utile après l'avènement du Christ, Henri de Gand prend par ailleurs l'exemple de la nourrice devenue inutile lorsqu'elle avait rempli son rôle et contribué à la croissance de l'enfant que ses parents lui avaient confié ${ }^{50}$; ce qui était initialement bon (porter le petit enfant dans les bras, le nourrir à la mamelle), devenait pernicieux lorsqu'il avait passé l'âge d'être porté ou allaités1.

L'enseignement des enfants forme le dernier volet de ce registre métaphorique. Selon Robert Grosseteste, la «loi pédagogue» avait eu pour fonction de détourner l'humanité du mal dans son âge déréglé et de la préparer, par des enseignements destinés aux enfants (puerilibus disciplinis), «à l'intelligence de la parfaite

47. Robert Grosseteste, De cessatione legalium, éd. cit., p. 46.

48. Alexandre de Halès, Summa theologica, Inquisitio 4, tr. 1, q. 10, cap. 2, éd. cit., p. 878.

49. Guillaume d'Auvergne, De legibus, éd. cit., p. 24a.

50. Henri de Gand, Summa quaestionum ordinarium, art. 9, q. 1, ad $4^{\text {um, }}$ éd. cit., fol. 71r.

51. Ibid., ad $5^{\text {um }}, e ́ d$. cit., fol. 71r. 
doctrine du maître parfait», le Christ, qui unus et solus est magister verus et perfectus ${ }^{52}$. Aussi la «loi pédagogue» conduisait-elle au Christ pour que les hommes fussent justifiés «non par la contrainte, la servitude ${ }^{53}$ et la discipline puérile du pédagogue, mais par la libre foi de Jésus Christ, qui possède la parfaite doctrine et rend l'homme parfait. Et c'est pourquoi, après que la foi est venue, nous ne sommes plus soumis au pédagogue, auquel sont seulement soumis les [hommes] imparfaits et les sujets des lois puériles $\gg^{54}$. Grosseteste souligne toutefois que «la loi [n'était] pas contraire à la foi, de même que le pédagogue [n'était] pas contraire au maître ou au père ». La fonction du pédagogue, suivant l'étymologie qu'il rappelle, consistait en effet à conduire l'enfant jusqu'au maître ${ }^{55}$. Henri de Gand a brièvement intégré le verset de l'Épître aux Galates dans un passage où il récuse la désignation de la Loi comme lex crudelitatis: "Le législateur divin n'avait d'autre intention que celle d'amener les hommes à la paix et à la concorde au moyen des préceptes de l'un et l'autre testaments. Il fallait y contraindre les uns, endurcis dans les péchés, par la crainte du châtiment et par de rudes préceptes; quant aux autres, qui étaient aptes à la vertu, il convenait de les y amener par l'amour de la justice et par des préceptes de douceur $»^{56}$. Dieu avait donc donné aux hommes «un pédagogue pour qu'ils le craignent, puis un maître pour qu'ils l'aiment $»^{57}$.

La métaphore de l'enfant et du pédagogue permettait ainsi d'expliquer la soumission puérile, servile et craintive envers la Loi ancienne comme l'étape nécessaire d'une progression naturelle. De même que les enfants devaient recevoir une alimentation adaptée et être entretenus, dans leur jeune âge, dans la crainte du pédagogue,

52. Robert Grosseteste, Expositio in epistolam sancti Pauli ad Galatas, éd. cit., p. 93.

53. Voir également Thomas d'Aquin, Commentaire de l'Épître aux Galates, éd. cit., chap. 4, leçon 1, v. 2, p. 154; Thomas applique au peuple juif l'état de contrainte du petit enfant qui, quoique maître de ses biens, ne diffère en rien d'un esclave tant qu'il est sous la dépendance d'autrui, parce qu'il ne jouit pas de sa libre volonté.

54. Robert Grosseteste, Expositio in epistolam sancti Pauli ad Galatas, éd. cit., p. 93.

55. Ibidem. $70 \mathrm{v}$.

56. Henri de Gand, Summa quaestionum ordinarium, art. 9, q. 1, éd. cit., fol.

57. Ibid., fol. 71r. 
ils devaient bénéficier d'un enseignement progressif, adapté à leurs capacités. Alexandre de Halès illustre ainsi la nécessité de faire varier les modes d'enseignement de l'Écriture sainte par la comparaison entre l'instruction des enfants et celle des adultes: les petits enfants ne devaient pas être instruits de la même façon que les adultes, car «comme le dit l'apôtre [1 Cor. 3, 1-2]: comme à des enfants en Jésus Christ, je ne vous ai nourris que de lait, et non de viandes solides, parce que vous n'en étiez pas capables; et à présent même vous ne l'êtes pas encore $»^{58}$. Allaités, portés, les hommes devaient être menés «pour ainsi dire par la main et par degrés progressifs jusqu'à la perfection $»^{59}$. Suivant Henri de Gand, il convenait de conduire graduellement les hommes vers la perfection. Aussi les choses plus faciles et moins parfaites avaient-elles été consignées dans l'Ancien Testament, avant que le Nouveau Testament livre des choses plus difficiles et plus parfaites, «en sorte que la première partie leur enseigne à fuir le péché par la crainte du châtiment, et la seconde à aimer les vertus par zèle pour la justice $»^{60}$. Cette exigence de progression graduelle se traduit concrètement dans la comparaison de l'enseignement de la loi divine avec l'enseignement humain. Olivi établit par exemple un rapport parfaitement explicite entre le don de la Loi fait «à un peuple rude et matériel, qui avait besoin, comme un enfant, d'un enseignement et d'une doctrine puérils, et qui ne pouvait saisir les raisons totales et formelles des vertus ni des perfections adaptées aux hommes parfaits », et l'enseignement de la lecture donné à un petit enfant (infantulus), auquel «on enseigne d'abord chaque lettre une par une, puis les syllabes, ensuite les mots et enfin les discours, et en ceux-ci d'abord les seules paroles, puis les figures. Sont en effet d'abord exprimées les choses particulières, avant que des expressions particulières on l'amène à saisir l'universel, de même qu'un certain temps est nécessaire pour qu'il s'élève des choses sensibles vers les choses intellectuelles, de même qu'à partir des effets et des signes des choses extérieures on en vient à pénétrer

58. Alexandre de Halès, Summa theologica, t. 1, Tractatus introductorius, q. 1, a. 5, éd. cit., p. 11.

59. Thomas d'Aquin, Summa theologiae, Ia IIae, q. 98, a. 6, Rome, Édition léonine, t. 7, 1892, p. 198.

60. Henri de Gand, Summa quaestionum ordinarium, art. 8, q. 5, éd. cit., fol. $67 \mathrm{v}$. 
leurs causes occultes $»^{61}$. En définitive, «il ne convient pas qu'un parfait législateur donne à un enfant la loi absolument parfaite qu'il aurait donnée à un homme presque accompli, mais il serait bon qu'il donne une loi qui convienne parfaitement à l'enfant, de même qu'une loi très parfaite convient à un homme très parfait $»^{62}$.

L'image des différentes étapes de l'apprentissage de la lecture renvoie à l' 'alphabet de l'honnêteté» et aux «rudiments de la religion ${ }^{63}$ par lesquels Guillaume d'Auvergne avait désigné la Loi ancienne, donnée «à un peuple encore rude et puéril», comme propédeutique à la réception de la «seconde partie [de la loi] comme plénitude et perfection [destinée] à un peuple déjà instruit $»^{64}$. Guillaume d'Auvergne a par ailleurs utilisé l'image de l'enseignement différencié dans une perspective dont l'originalité a été soulignée par Beryl Smalley ${ }^{65}$. Son traité De legibus comporte en effet une critique de l'interprétation commune qui limitait l'interprétation des préceptes à leur sens spirituel, et considérait les legalia comme un voile ou une simple préfiguration de la loi nouvelle ${ }^{66}$. Selon Guillaume d'Auvergne, certains préceptes apparemment absurdes avaient des causes justes et raisonnables et devaient être compris dans leur sens littéral. La Loi avait en outre une multiplicité de sens que tous ses destinataires n'avaient pu saisir au même degré: «Il est manifeste que le livre de toute la Loi [...]

61. Pierre de Jean Olivi, De legalibus, Napoli, Bibl. Naz., XII A 23, fol. 9ra: «Primo quia in ipso innuit se datam populi rudi et materiali et quasi puerili disciplina et doctrina egenti, qui totales et formales rationes virtutum et omnium perfectionum perfectis competentium capere non posset; iuxta quod infantulus primo docetur unamquamque litteram sigillatim, ac deinde sillabas, et postmodum dictiones et tandem orationes, et in hiis primo solas voces et deinde figurationes. Primo etiam exprimuntur particularia antequam ex particularibus exprimentis inducat et recolligat universale, sic etiam ex sensibilibus ad intellectualia vix post longum tempus adsurgit, sic ab effectibus et signis extra patentibus vix intratur ad causas eorum occultas».

62. Ibid., fol. 9va: «Non enim est perfecti legis latoris dare puero legem sic simpliciter perfectam sicut viro mox perficiendo, sed bene esset eius dare eam sic perfecte competere puero sicut perfectissima convenit viro perfectissimo».

63. Guillaume d'Auvergne, De legibus, cap. 1, éd. cit., p. 23b: «Lex vetus rudi adhuc et puerili populo, tanquam alphabetum honestatis, tanquam elementa initialia religionis tradita est ».

64. Ibidem: «Pars vero secunda tanquam plenitudo atque perfectio erudita iam populo».

65. Beryl Smalley, «William of Auvergne, John of la Rochelle, and St. Thomas Aquinas on the Old Law», loc. cit., p. 147-149.

66. Ibid., p. 147. 
fut donné à tout le peuple des Hébreux, en sorte qu'il soit instruit et enseigné. Mais il ne convient pas que le même enseignement (lectio) soit proposé aux simples et aux doctes. Quel maître, dans son école, ne propose pas à chacun de ses élèves un enseignement adapté à ses capacités? Et Dieu plus encore, instructeur de tous (eruditor omnium) dans son école où il lui fallait instruire et enseigner ce peuple, a proposé un enseignement adapté aux capacités de chacun des membres de ce peuple, et donc des rudiments aux simples, des choses plus difficiles aux élèves plus avancés et des choses plus sublimes aux doctes. Et parce que parmi les doctes il y avait divers degrés, en sorte que certains étaient éminents, d'autres plus éminents encore, et qu'il y avait parmi eux une grande variété, chaque élève a nécessairement reçu, dans l'école de Dieu, une doctrine qui lui convienne, non au moyen d'un enseignement unique, mais par une grande variété et une multitude d'enseignements (varietatem ac multitudinem lectionum). Elle ne leur a été donnée que dans un seul livre, qui seul était enseigné dans l'école de Dieu. Dans ce livre, Dieu a rassemblé des enseignements aussi variés et nombreux (varietatem ac multitudinem lectionum) que l'exigeait la variété et la multitude des élèves (varietas et multitudo lectorum) ${ }^{67}$.

En définitive, le modèle d'unité naturelle et de succession didactique des deux testaments, ainsi que la mise en lumière de l'indissolubilité des fonctions divines de législateur et de maître, assignaient un cadre fondamentalement légal à l'enseignement théologique et pouvaient servir de point d'appui à une réflexion sur la capacité humaine à construire des normes fondées sur la loi divine. Si les particularia de l'Ancien Testament avaient fait place à une Loi nouvelle indéterminée, celle-ci formait le cadre d'une entreprise d'interprétation et de production humaine de normes particulières. Le mouvement historique et didactique qui conduisait des préceptes de la Loi ancienne aux normes chrétiennes issues des préceptes universels et généraux de la Loi nouvelle posait le problème du travail spécifique des théologiens à l'intérieur d'un système clos.

67. Guillaume d'Auvergne, De legibus, cap. 16, éd. cit., p. 47b. 


\section{LES ARCHITECTES DE LA LOI NOUVELLE}

Les deux testaments formaient-ils un système clos? Lorsqu'au $\mathrm{XIII}^{\mathrm{e}}$ siècle le théologien Henri de Gand commente le passage de l'Évangile de Jean où le Christ dit: «J'ai encore beaucoup de choses à vous dire; mais vous ne pouvez les porter présentement. Quand cet Esprit de vérité sera venu, il vous enseignera toute vérité ${ }^{68}$, c'est précisément en relation avec la question de savoir si l'Écriture sacrée était parfaitement consignée dans l'Ancien et le Nouveau Testament (Utrum perfecte conscripta est in duobus testamentis ${ }^{69}$ ): fallait-il attendre un complément de vérité, voire un évangile du «troisième âge» - celui du Saint-Esprit - conformément à la division joachimite de l'histoire du salut ${ }^{70}$ ? Henri de Gand répond que la Loi avait été accomplie par le Christ; que les deux livres de la Bible formaient ensemble une totalité parfaite et que les trois âges de l'homme correspondaient respectivement à la loi de nature, à la Loi de Moïse et à celle de l'Évangile, laquelle durerait jusqu'à la fin des temps. L'annonce rapportée par l'Évangile de Jean ne devait pas se comprendre comme celle d'un complément de vérité, mais comme celle d'une intelligence plus parfaite de la vérité révélée et formellement contenue dans l'Évangile ${ }^{71}$ : «[Le Christ] n'a pas promis, en effet, que l'Esprit enseignerait une vérité supplémentaire ou plus parfaite que celle qu'il avait lui-même enseignée, mais plutôt qu'il expliquerait la vérité qu'il n'avait pas exposée dans l'Ancien Testament et dans sa doctrine évangélique $»^{72}$. Cette mise au point est étayée d'un développement sur les progrès humains dans l'intelligence de la vérité. Le Christ avait complété les enseignements de l'Ancien Testament de deux façons: en abolissant l'observance littérale des préceptes cérémoniels et en révélant leur signification spirituelle; en complétant les préceptes moraux et en étendant leur portée. Les écrits des apôtres avaient poursuivi l'œuvre du Christ

68. Jean 16, 12-13, cité par Henri de Gand dans la Summa quaestionum ordinarium, art. 8, q. 6, fol. 68r: "Adhuc multa habeo vobis dicere, sed non potestis portare modo. Cum autem venerit ille spiritus veritatis, docebit vos omnem veritatem ».

69. Henri de Gand, Summa quaestionum ordinarium, art. 8, q. 6, éd. cit., fol. 68r-70r.

70. Ibid., fol. 68 r.

71. Ibid., fol. 69r.

72. Ibid., fol. $68 \mathrm{v}$. 
sur l'Ancien Testament en appliquant la méthode transmise par le message évangélique du Christ et expliqué les enseignements évangéliques du Christ, qui n'avait pas lui-même expliqué toutes ses paroles difficiles. Les Pères à leur tour avaient continué l'œuvre des apôtres, avec une moindre autorité toutefois, puisque l'Église ne pouvait être sûre que le Saint-Esprit parlait à travers eux comme il avait parlé à travers les apôtres. Enfin, les docteurs catholiques avaient pris le relais des Pères et « de même que les apôtres avaient exposé les Écritures que n'avait pas exposées le Christ sur le modèle de celles qu'il avait exposées », ils devraient «exposer celles que ni le Christ ni les apôtres n'avaient exposées sur le modèle de celles qu'ils avaient exposées, jusqu'à la fin des temps, sans se satisfaire des expositions anciennes $\gg^{73}$. Le temple de Dieu serait ainsi édifié à travers les âges. La tâche de compréhension et d'explication des Écritures se poursuivrait jusqu'à la consommation de toutes choses. La connaissance des Écritures ne cesserait de croître avec le temps ${ }^{74}$.

Le souci d'édification du «temple de Dieu» fait certes référence à une métaphore commune ${ }^{75}$. Celle-ci présente toutefois la particularité de renvoyer aux constructions intellectuelles fondées sur les textes sacrés. Au IV ${ }^{\mathrm{e}}$ siècle, Lactance décrivait déjà dans ces termes la mission, assignée par Dieu au Christ «professeur» et «loi vivante», de fonder «un nouveau temple». Dans l'homélie de Jean Scot Érigène sur le prologue de l'Évangile de Jean, c'est l'Écriture même qui forme l'édifice (monumentum Christi est divina scriptura ${ }^{76}$ ): «Le tombeau du Christ est la sainte Écriture en laquelle, protégés par le poids de la lettre comme l'était le tombeau par la pierre, les mystères de sa divinité et de son humanité sont

73. Ibid., fol. $69 \mathrm{v}$.

74. Sur l'idée de progrès dans la pensée humaine, à une époque marquée par l'intégration de savoirs nouveaux qui contribuent à élargir le champ de la théologie et à affiner ses méthodes d'enquête et d'analyse, on verra notamment Gilbert Dahan, «Ex imperfecto ad perfectum: le progrès de la pensée humaine chez les théologiens du XIII ${ }^{\mathrm{e}}$ siècle», dans Id., Lire la Bible au Moyen Âge. Essais d'herméneutique médiévale, Genève, Droz, 2009, p. 409-425.

75. Comme on l'a vu dans les textes sur l'accomplissement de la loi par le Christ.

76. Jean Scot Érigène, Homélie sur le prologue de Jean, introduction, texte critique, traduction et notes Édouard Jeauneau, Paris, Cerf (SC 151), 1969, chap. 3, p. $212-214$. 
renfermés $\gg^{77}$. Courant avec Pierre au tombeau, Jean y arrive le premier, car il représente la contemplation qui, «déjà pleinement purifiée, pénètre avec plus d'acuité et de promptitude dans le secret des divines Écritures que ne le fait l'action qui doit encore être purifiée $»^{78}$. Mais c'est Pierre qui y entre le premier: «Pierre est le symbole de la foi, Jean signifie l'intelligence. Et parce qu'il est écrit: À moins de croire, vous ne comprendrez pas [Isaïe 7, 9], la foi entre nécessairement la première dans le tombeau de la sainte Écriture; à sa suite, l'intelligence y pénètre, et c'est la foi qui lui en prépare l'entrée $»^{79}$. Au tournant des $\mathrm{XII}^{\mathrm{e}}$ et XIII ${ }^{\mathrm{e}}$ siècles, Pierre le Chantre comparait les trois termes de la «pratique de l'étude de l'Écriture sacrée» (lectio, disputatio, predicatio) aux fondations, aux murs et au toit d'un édifice doctrinal dans lequel la dispute devait garantir la pleine intelligence des Écritures et la pratique d'une prédication fidèle ${ }^{80}$. Les textes scolastiques révèlent du reste que les maîtres en théologie du $\mathrm{XIII}^{\mathrm{e}}$ siècle se concevaient eux-mêmes comme des architectes, auteurs des plans et des règles communiqués aux pasteurs, «ouvriers» ou «artisans » voués à édifier directement les âmes: «Dans n'importe quel ouvrage, celui qui dispose le plan est, dans l'absolu, meilleur - et on l'appelle l'architecte - que l'ouvrier qui exécute l'ouvrage suivant ce plan disposé par un autre [...]. Dans l'édifice spirituel, ceux qui s'appliquent en particulier au soin des âmes, par exemple en administrant les sacrements ou en accomplissant quelque action particulière de cette sorte, sont comme des ouvriers manuels; mais les évêques, qui ordonnent et disposent la façon dont cet office doit être exercé, sont comme des artisans spirituels [...]. Et de la même façon, les docteurs en théologie, qui recherchent et enseignent la façon dont les autres doivent procurer le salut des âmes, sont comme les artisans principaux $»^{81}$.

Si le sacrifice du Christ semble pouvoir résoudre la difficulté liée à sa double fonction de loi et de législateur, la contradiction liée à la nécessité de construire le «temple de Dieu» alors même

77. Ibidem.

78. Ibid., p. 212-215.

79. Ibid., p. 214-215.

80. Pierre le Chantre, Verbum adbreviatum, I, 1, éd. M. Boutry, Turnhout, Brepols (CCCM 196), 2004, p. 9.

81. Thomas d'Aquin, Quodlibet I, 14, éd. René-Antoine Gauthier, Rome, 1996, t. 25-2, p. 195-196. 
que l'édifice de l'Écriture sainte était achevé pouvait se résoudre par l'exigence d'explicitation d'une vérité révélée dont la totalité parfaite était contenue dans les deux livres de la Bible. Elle devait être expliquée, exposée, visitée comme un «monument» dans lequel la foi devait précéder et éclairer l'intellect. L'homologie formelle entre l'architecture gothique et la pensée scolastique observée par Panofsky confirme à la fois la tâche de construction et le type de fonction assignés aux docteurs: la théologie est une élaboration formelle et rationnelle du donné de la foi, qui n'a pas pour but de prouver, mais de manifester la vérité de la foi, tout en rendant «palpables et explicites l'ordre et la logique» de ses propres schèmes de raisonnement ${ }^{82}$. L'architecte scolastique ne vise pas tant à construire de novo qu'à ressaisir, par l'explicitation et la clarification, le monument scripturaire de la «Loi nouvelle». La spécificité de son intervention, dans la chaîne des interprètes qui ont constitué le savoir chrétien, tient à une mutation majeure du régime d'accession à la vérité. À partir du XII ${ }^{\mathrm{e}}$ siècle, sa tâche d'explicitation s'inscrit dans le cadre rationnel du débat contradictoire. Il s'agit, suivant les termes d'Abélard, de construire la vérité par l'enquête en confrontant les autorités dissonantes. C'est du reste à la méthode des juristes que Roger Bacon assigne la tâche de conciliation des contradictions: «Lorsqu'on enseigne et qu'on prêche, on opère principalement trois choses dans un texte: des divisions par membres variés, à la manière des artiens; de fortes concordances, à la manière des juristes; des consonances rythmiques, à la manière des grammairiens $»^{83}$. La théologie met ainsi en œuvre une rationalité qui donne à la norme un autre fondement que le fondement mystique de la foi ou le fondement dogmatique de l'Église, sans les excepter. Les articles de foi constituant les principes de la science théologique, «c'est [...] simultanément l'exigence technique de la science et le sens religieux qui imposent à la théologie de partir de la foi [...], puisque c'est la foi qui assure la continuité de la «science de Dieu» (subalternante) à la science théologique (subalternée) $\gg^{84}$.

82. Erwin Panofsky, Architecture gothique et pensée scolastique, [1951], Paris, Éditions de Minuit, 1967, p. 95.

83. Roger Bacon, Opus minus, cité dans Erwin Panofsky, op. cit., p. 119, n. 49.

84. Marie-Dominique Chenu, La Théologie comme science au XIII siècle, 1927, Paris, Vrin, 3e éd. 1957, p. 73. 
On a montré ailleurs ${ }^{85}$ la façon dont les théologiens parisiens du XIII $^{\mathrm{e}}$ siècle ont revendiqué et exercé leur capacité à produire des normes pour la société chrétienne en résolvant des questions concrètes, analogues aux casus juridiques, portant sur des situations communes, voire précisément liées à l'actualité contemporaine. On a postulé que les solutions théologiques, variables ou divergentes, sans vigueur coercitive ni effectivité immédiate, n'étaient toutefois pas dépourvues d'efficacité ni de pertinence normative. Ce postulat se fondait à la fois sur l'observation d'un contexte médiéval où les normes, laïques et ecclésiastiques, présentaient des caractères similaires, et sur l'analyse des cadres d'énonciation et de la teneur même des solutions magistrales. Le mouvement historiographique des vingt ou trente dernières années conduisait du reste à élargir le champ de l'étude des normes médiévales en y intégrant des «structures normatives » distinctes de la norme juridique et conçues comme « valeurs de référence qui disciplinent la société » ${ }^{86}$, stimulant un questionnement multiple sur le fondement des normes, la place du droit dans leur élaboration, leur essence autoritaire et coercitive ou les rapports entre normes et pouvoir. Dans le secteur des études scolastiques, les travaux d'Alain Boureau ont largement contribué à éclairer les rapports denses et complexes de la théologie et du droit au sein de la «sphère de savoirs et de méthodes organiquement liés $\gg^{87}$ qui constituent, précisément, la scolastique médiévale. C'est sur cette toile de fond, au cœur de l' "épistémè scolastique »" notamment définie par l'interaction de la théologie et du droit, que l'on voudrait montrer brièvement, à partir des cas concrets du sabbat

85. Je me permets de renvoyer à Elsa Marmursztejn, L'Autorité des maîtres. Scolastique, normes et société au XIII siècle, Paris, Les Belles Lettres, 2007; on verra également «Une fabrique de la norme au XIII ${ }^{\mathrm{e}}$ siècle : l'Université de Paris », dans Véronique Beaulande, Julie Claustre et Elsa Marmursztejn dir., La fabrique de la norme. Lieux et modes de production des normes au Moyen Âge et à l'époque moderne (à paraître).

86. Claude Gauvard, Alain Boureau, Robert Jacob, Charles de Miramon, «Les normes», dans Jean-Claude Schmitt et Otto-Gerhard Oexle (dir.), Les Tendances actuelles de l'histoire du Moyen Âge en France et en Allemagne, Paris, Publications de la Sorbonne, 2002, p. 469.

87. Alain Boureau, «Droit et théologie au XIII ${ }^{\mathrm{e}}$ siècle», Annales ESC, 47, $\mathrm{n}^{\circ}$ 6, 1992, p. 1113-1125; Id., L'Empire du livre. Pour une histoire du savoir scolastique (1200-1380), Paris, Les Belles Lettres, 2007, p. 14; on verra plus largement l'entreprise de La raison scolastique, dont L'Empire du livre forme le second volume.

88. Alain Boureau, L'Empire du livre, op. cit., p. 14. 
et de la dîme, la façon dont les lieux de production des normes chrétiennes ont constitué des lieux de réactivation de la tension entre Loi ancienne et Loi nouvelle.

\section{PérenNité et MUTATION DeS NORMES VÉTÉROTESTAMENTAIRES}

Le choix de faire porter l'analyse sur les préceptes de l'observance sabbatique et de la dîme n'est pas ici purement arbitraire. Dans les Quodlibets, qui ont constitué le lieu privilégié de la discussion théologique sur des cas concrets, épineux ou habituels dans l'université du XIII ${ }^{\mathrm{e}}$ siècle, la réflexion sur l'articulation de la nouvelle et de l'ancienne Loi affleure précisément à l'occasion de questions sur la dîme ou sur le repos dominical. L'affinité structurelle entre les deux préceptes est du reste clairement établie par Thomas d'Aquin dans un texte quodlibétique de 1269: «Certains préceptes de la Loi sont purement moraux [...]; certains sont purement cérémoniels [...]; certains sont moyens (media), d'un certain point de vue moraux, et d'un certain point de vue cérémoniels, de même que le précepte de l'observance du sabbat est moral dans la mesure où il faut qu'un temps soit consacré au repos pour vaquer aux choses divines, ce que dicte aussi la raison naturelle; mais que le septième jour y soit consacré, c'est Dieu qui l'a déterminé pour figurer quelque chose, et cela est donc cérémoniel. De même, donc, le précepte selon lequel il faut acquitter les dîmes est moral d'un certain point de vue, dans la mesure où ceux qui vaquent au service divin pour tout le peuple sont entretenus par les contributions du peuple, de même que ceux qui servent dans les autres offices de la chose publique sont entretenus par le peuple [...]. Mais quant à la quotité déterminée de la dîme, elle ne relève pas du droit naturel ni ne constitue un précepte moral, mais elle est cérémonielle, dans la mesure où elle est destinée à figurer quelque chose relative au Christ, voire judicielle, convenant à ce peuple qui comptait une multitude de ministres dont l'entretien exigeait une telle taxation $»^{89}$.

Substitué au précepte de l'observance sabbatique, le précepte du repos dominical est, selon Henri de Gand, «fondé sur un édit

89. Thomas d'Aquin, Quodlibet II, 8 («Circa decimis que debentur ministris sacramentorum, utrum aliquis propter consuetudinem possit excusari ne decimas solvat»), éd. René-Antoine Gauthier, Rome, 1996, vol. 2, p. 225-226. 
général de la loi naturelle, spécifié par un édit positif de l'Église. Car l'édit de la loi de nature, inscrit dans les tables du cœur, stipule que tout homme ayant l'usage de la raison doit vaquer à certains moments, toutes affaires cessantes, au culte divin et à la vénération de Dieu. Mais ensuite, parce que les hommes, tournés vers les préoccupations temporelles, négligeaient de déterminer pour euxmêmes les moments réservés au culte divin, l'Église détermina par un statut ce moment que la loi naturelle ne déterminait pas, parce que ce qui est induit de façon singulière est mieux respecté que ce qui est proposé par un précepte général. Et [l’Église] ordonna que le jour du Seigneur fût celui de la résurrection du Christ en un homme nouveau, de même que dans la Loi ancienne le jour du sabbat avait été établi pour préfigurer le repos du Christ dans la mort de l'homme ancien ${ }^{90}$. La nature mixte du précepte autorisait ainsi son transfert d'un régime légal à l'autre; sa qualité de précepte moral, fondé en droit naturel - et qui expliquait du reste sa présence et son rang parmi les préceptes décalogiques ${ }^{91}$ - assurait sa légitime pérennité; la détermination du moment consacré à son observance avait incombé à l'Église: l'observance du repos dominical sous la nouvelle loi n'avait pas succédé à celle du sabbat «en vertu de la vigueur du précepte de la Loi», mais «en vertu d'une constitution de l'Église et de la coutume du peuple chrétien $»^{92}$.

La mutation de la partie cérémonielle du précepte ne résultait pas d'une décision purement arbitraire. Elle se fondait sur une interprétation spirituelle du «repos» (quies) commémoré dans l'observance sabbatique. Dans son traité De decem mandatis, Robert Grosseteste souligne la singularité du troisième commandement, qui clôt la brève série des commandements de la première table relatifs à l'amour de Dieu: «Sur la totalité de ces dix préceptes, seul celui qui est exposé ici à propos du sabbat doit être observé à la manière d'une figure (figurate), qu'il nous faut comprendre, et nous ne devons pas le recevoir comme devant être célébré par le loisir

90. Henri de Gand, Quodlibet 1, 41 («Utrum liceat in die dominico tenere forum rerum venalium»), éd. Raymond Macken, Louvain-Leyde, Leuven University Press-Brill, 1979, p. 230-231.

91. Cf. Thomas d'Aquin, Summa theologiae, IIa IIae, q. 122, a. 4, ad $1^{\text {um }}$, Rome, Édition léonine, t. 9, 1897, p. 478: «Praeceptum de sanctificatione sabbati ponitur inter praecepta Decalogi inquantum est praeceptum morale, non inquantum est caeremoniale».

92. Ibid., p. 479. 
corporel, puisque en effet c'est le repos spirituel qui est signifié par le sabbat ${ }^{93}$. À la différence des autres préceptes - sic observantur, ut sonant -, le précepte de l'observance sabbatique ne doit pas être respecté ad litteram, par l'abstention de toute œuvre corporelle, «comme l'observent les juifs; et le fait même qu'ils l'observent parce qu'il a été ainsi ordonné, on juge qu'il faut en rire, à moins qu'il ne signifie quelque autre repos spirituel ${ }^{94}$, en l'occurrence le repos «saint et certain qui ne se trouve qu'en Dieu ${ }^{95}$. Dans le traité De cessatione legalium, Grosseteste revient sur l'interprétation du précepte sabbatique, auquel il prête la signification primordialement morale de cessatio a peccato ${ }^{96}:$ :'œuvre servile» interdite par le Deutéronome $(5,14)$ est identifiée au péché, car celui «qui commet le péché est l'esclave du péché» (Jean 8,34$)$; elle procède du péché originel, car «si l'homme n'avait pas péché, il ne serait soumis à aucune des œuvres serviles qu'exige la condition pénale de cette vie. De même donc que l'effet désigne la cause, de même l'œuvre servile désigne le péché. Le respect du sabbat (sabatizacio), qui est, par l'écriture de la Loi, vacance des œuvres serviles, est par la règle susdite la cessation du péché ${ }^{97}$. Il apparaît par conséquent «que le sabbat est perpétuel, et qu'il doit toutefois cesser. Puisque cela [demeurer perpétuellement, cesser] ne peut affecter la même chose, comment comprendre de façon plus évidente, lorsqu'on dit que le sabbat est perpétuel, qu'il s'agit du sabbat moral, le sabbat littéral étant appelé à cesser ? Et [...] il est tout à fait évident que lorsqu'il dit que le sabbat est un pacte perpétuel ${ }^{98}$, l'auteur avait l'intention de nous enseigner que la vacance du péché était un pacte perpétuel entre Dieu et l'homme. Et cette perpétuité du pacte n'est pas attribuée au sabbat littéral ${ }^{99}$, compris comme signacio perpetua sabato spirituali ${ }^{100}$.

Dans la Somme de théologie, traitant du précepte de la sanctification du sabbat comme précepte cérémoniel, «dans

93. Robert Grosseteste, De decem mandatis, éd. Richard C. Dales et Edward B. King, The British Academy, Oxford University Press, 1987, p. 27.

94. Ibidem.

95. Ibidem.

96. Id., De cessatione legalium, éd. cit., p. 52.

97. Ibidem.

98. Exode 31, 16-17.

99. Robert Grosseteste, De cessatione legalium, éd. cit., p. 53.

100. Ibid., p. 54. 
la mesure où dans ce précepte un temps spécial est déterminé en signe de la création du monde», Thomas d'Aquin procède méthodiquement à l'exégèse de ses différentes significations: le précepte est «également cérémoniel dans un sens allégorique, en ce qu'il fut la figure du repos du Christ au sépulcre, le septième jour. Et de même dans un sens moral, en ce qu'il signifie la cessation de tout acte de péché et le repos de l'esprit en Dieu [...]. Et il est également cérémoniel dans un sens anagogique, en ce qu'il préfigure le repos de la fruition de Dieu qui aura lieu dans la patrie ${ }^{101}$. Le précepte de l'observance sabbatique suivait ainsi le régime général de la Loi ancienne, dont les préceptes moraux étaient conservés simpliciter et absolute, mais dont les préceptes cérémoniels ne demeuraient que quantum ad veritatem per ea figuratam ${ }^{102}$. L'obligation morale - de consacrer un temps au culte divin avait été perpétuée. La détermination - cérémonielle - du moment à consacrer au culte divin avait été renouvelée par l'Église: «Le sabbat, qui signifiait la première création, est remplacé par le dimanche, commémorant la créature nouvelle inaugurée dans la résurrection du Christ. Et de même, de nouvelles solennités ont succédé aux autres solennités de l'ancienne Loi, parce que les bienfaits accordés à ce peuple signifient les bienfaits qui nous ont été concédés par le Christ » ${ }^{103}$. Cette diversité même de sens expliquait la place du précepte dans le Décalogue: la célébration du sabbat commémorait le premier et principal bienfait de Dieu, celui de la Création. La raison du précepte se trouvait dans l'Exode $(20,11)$ : «Dieu fit le ciel et la terre en six jours». Aussi, «parmi les bienfaits futurs, qu'il fallait préfigurer, le principal et le final était le repos de l'esprit en Dieu, soit dans le présent par la grâce, soit dans l'avenir par la gloire, qui était aussi figurée par l'observance du sabbat [...]. Mais les autres solennités sont célébrées en raison de certains bienfaits particuliers et provisoires, comme le rite pascal en raison du bienfait passé de la libération d'Égypte, et [comme signe] de la passion future du Christ, qui s'est accomplie dans le temps et nous a conduits dans le repos d'un sabbat spirituel. Et c'est pourquoi, omettant toutes

101. Thomas d'Aquin, Summa theologiae, IIa IIae, q. 122, a. 4, ad $1^{\text {um }}$,éd. cit., p. 478.

102. Ibid., Ia IIae, q. 103, a. 3, ad. $1^{\text {um }}$, Rome, Édition léonine, t. 7, 1892, p. 255.

103. Ibid., ad $4^{\mathrm{um}}$, éd. cit., p. 255. 
les autres solennités et sacrifices, il est fait mention du seul sabbat parmi les préceptes du Décalogue ${ }^{104}$.

Le précepte sabbatique se présente ainsi comme un point d'application de la réflexion théologique particulièrement révélateur de la conception dialectique de la relation entre l'ancienne et la nouvelle $\mathrm{Loi}^{105}$. La justification du passage de l'observance sabbatique au repos dominical ne s'est fondée ni sur la nécessité générale d'abolir les préceptes cérémoniels, ni sur la seule interprétation spirituelle du sabbat. La réflexion théologique du $\mathrm{XIII}^{\mathrm{e}}$ siècle ne s'est pas cantonnée dans l'exégèse. Stimulée par la singularité de l'inscription du sabbat parmi les préceptes du Décalogue, elle s'est appliquée à en révéler la double structure normative: une partie cérémonielle détachable se superposait à un socle moral permanent ; le transfert du précepte moral s'accomplissait par la substitution du fondement du droit naturel au fondement légal vétérotestamentaire; la mutation du précepte cérémoniel se fondait sur la manifestation du sens seulement figuré ou préfiguré par le sabbat, accompli par l'avènement et la passion du Christ, et finalement traduit en norme par l’Église.

Si elle pose également le problème de la perpétuation d'un précepte inscrit dans la Loi ancienne, l'obligation d'acquitter la dîme ne présente pas le même profil problématique que le précepte sabbatique. Située hors du Décalogue, sans fondement explicite dans la loi nouvelle, elle constitue un droit de l'Église sur les biens temporels des laïcs bénéficiaires de ses services spirituels. La question ecclésiologique des modes d'appropriation des biens temporels par l'Église se complique donc ici de la question des relations d'échange, parfois conflictuelles, avec les laïcs. Les amples discussions scolastiques sur la dîme - étudiées ailleurs, et dans le détail desquelles on n'entrera que brièvement ici ${ }^{106}$ - ont porté sur l'institution et sur le régime juridique de la dîme; elles ont surgi d'autre part d'une série de contradictions ou d'exceptions

104. Ibid., Ia IIae, q. 100, a. 5, ad $2^{\text {um }}$,éd. cit., p. 211-212.

105. Gilbert Dahan le compte parmi les grands thèmes de la polémique sur la vétusté du judaïsme et en évoque brièvement le traitement dans Les intellectuels chrétiens et les juifs au Moyen Âge, Paris, Cerf, 1990, p. 505-506.

106. Je me permets de renvoyer à Elsa Marmursztejn, «Débats scolastiques sur la dîme au Moyen Âge central», dans Michel Lauwers dir., La dîme au Moyen Âge. Histoire d'un prélèvement ecclésiastique, Brepols, Collection d'études médiévales de Nice, vol. 12 (à paraître), dont les analyses qui suivent sont largement issues. 
(exemptions de fait, variations locales de quotité, détention de dîmes par des laïcs ou des religieux, disjonction entre dîme et territoire paroissial...) qui semblaient saper le droit de l'Église. Sur ce terrain occupé par les canonistes, les théologiens ont mené une enquête exégétique et juridique en profondeur, fondée sur la scansion juridique de l'histoire du salut (avant la Loi, sous la Loi, sous la grâce).

Dans la somme franciscaine dite d'Alexandre de Halès, la dîme est ainsi inscrite dans le processus de révélation de la nature du Sauveur. À chaque étape de cette révélation correspondait une offrande adéquate, qui manifestait la foi, implicite ou explicite, qui constituait la condition du salut. La personne du Sauveur avait ainsi été révélée dans sa nature divine de Conditor à Abel, qui l'avait honorée des prémices; dans sa nature créée de Mediator à Noé, qui l'avait honorée d'offrandes et de sacrifices; dans sa nature de Redemptor à Abraham, qui l'avait honorée de la dîme parce qu'elle désignait la nature humaine d'après la parabole de la dixième drachme (Luc 15, 8-10) ${ }^{107}$. En montrant que, dans la succession des époques, les signes des grâces spirituelles avaient gagné en évidence ${ }^{108}$, et que la dîme honorait adéquatement la nature humaine du Christ, Alexandre de Halès se livrait une exégèse spirituelle de l'obligation vétérotestamentaire. Quant à sa quotité, la dîme résultait d'une «institution divine» qui répondait à la division en douze tribus du peuple récipiendaire de la Loi et à la nécessité d'entretenir la tribu des lévites, voués au service divin et dépourvus de toute possession ${ }^{109}$, et qui devaient eux-mêmes verser un dixième de cette dîme aux prêtres descendants d'Aaron ${ }^{110}$. Le précepte de l'ancienne Loi n'avait toutefois pas été confirmé par la nouvelle. Les théologiens ont en effet généralement considéré que le passage de l'Évangile de Matthieu $\left(23,23^{111}\right)$ dans lequel une infime minorité d'entre eux avaient prétendu lire cette confirmation,

107. Alexandre de Halès, Summa theologica, pars 2, inq. 3, tract. 2, q. 3, tit. 1, cap. 1, éd. cit., p. 729b-730a.

108. Ibid., p. 730a.

109. Thomas d'Aquin, Summa theologiae, IIa IIae, q. 87, a. 1, éd. cit., p. 227.

110. Alexandre de Halès, op. cit., cap. 7, a. 2, éd. cit., p. 748.

111. «Malheur à vous, scribes et pharisiens hypocrites, qui payez la dîme de la menthe, de l'aneth et du cumin, et qui avez abandonné ce qu'il y a de plus important dans la loi, à savoir la justice, la miséricorde et la foi. C'étaient là les choses qu'il fallait pratiquer, sans néanmoins omettre les autres». 
s'appliquait aux juifs et relevait du régime de l'Ancien Testament ${ }^{112}$. La tâche des théologiens consistait donc à étayer le droit de l'Église en construisant une norme chrétienne de la dîme sur des fondements essentiellement vétérotestamentaires.

Comme on l'a constaté chez Thomas d'Aquin, les théologiens ont résolu le problème de la dîme d'une façon structurellement analogue à la résolution du problème du précepte sabbatique: l'obligation indéterminée de la dîme relevait d'un "précepte de la loi naturelle» (Godefroid de Fontaines ${ }^{113}$ ), «inscrit quant à sa substance dans le cœur de l'homme» (Guillaume d'Auxerre ${ }^{114}$ ), et procédant de la raison «universelle» (Alexandre de Halès ${ }^{115}$ ) ou «naturelle» (Thomas d'Aquin $\left.{ }^{116}\right)$. Ce précepte de droit naturel fondait l'obligation générale de rétribution des prêtres. Il ne fondait pas la quotité précise de la dîme, dont la détermination avait incombé à l'Église. Le précepte de la dîme était donc conçu, à l'instar du précepte sabbatique, comme un «précepte mixte». L'avènement de la loi évangélique avait fait cesser l'obligation pro quota illa, mais elle demeurait pro illo quod erat de iure legis naturae ${ }^{117}$. En tant que quotité, la dîme ne relevait pas de la loi mosaïque, mais d'une «nouvelle institution de l'Église» ${ }^{118}$. Pour un théologien comme Gérard d'Abbeville, qui soutenait que l'obligation de la dîme avait été confirmée par l'Évangile de Matthieu (23, 23), la quotité du dixième signifiait, sous le régime de la loi évangélique, la soumission envers Dieu, l'accomplissement moral du Décalogue, la perfection dans les œuvres de charité, la restauration de l'ordre décimal ${ }^{119}$. Dans une optique générale différente, le franciscain John Peckham opposait, à l'idée du caractère purement cérémoniel de la quotité, les «préceptes du Siège apostolique» contenus au titre

112. Cf. Guillaume d'Auxerre, Summa aurea, lib. 3, tr. 51, cap. 3, éd. Jean Ribaillier, Paris-Grottaferrata, t. 18-2, 1986, p. 1000; Thomas d'Aquin, Quodlibet II, 8, éd. cit., p. 224; Henri de Gand, Quodlibet IV, 28, éd. Paris, 1518, fol. 145 r.

113. Godefroid de Fontaines, Quodlibet XI, 12, éd. cit., p. 60

114. Guillaume d'Auxerre, Summa aurea, lib. 3, tr. 51, cap. 2, éd. cit., p. 995.

115. Alexandre de Halès, Summa theologica, tit. De decimis, cap. 1, éd. cit., p. 728 b.

116. Thomas d'Aquin, Summa theologiae, IIa IIae, q. 87, a. 1, éd. cit., p. 227.

117. Henri de Gand, Quodlibet IV, 28, éd. cit., fol. 145 r.

118. Ibidem.

119. Gérard d'Abbeville, Quodlibet I, 14, Paris, BnF, lat. 16405, fol. 31rb; Vatican, lat. 1015, fol. 40rb. 
De decimis du Liber extra. Le dixième était dû parce qu'il était «l'offrande de l'homme qui est la dixième drachme, comme le dit Luc 15,8 , et signifie la rédemption ${ }^{120}$. L'argument de la perfection du dixième justifiait que l'on attribuât à Dieu sa perfection et que l'on retînt l'imperfection, ce qui était plus nécessaire sous le régime du Nouveau Testament que sous celui de l'Ancien: «La dîme doit être donnée comme elle l'était alors, et certainement même d'autant plus que le Nouveau Testament est plus parfait que l'Ancien ${ }^{121}$. Thomas d'Aquin justifiait a contrario les variations de la quotité par le fait que l'Église, dotée du pouvoir de légiférer en matière de culte divin, pouvait fixer librement la quotité de ce qui serait versé à ses ministres; c'est "pour qu'il y ait quelque consonance entre l'Ancien et le Nouveau Testament [qu']elle avait décrété que la taxation de l'Ancien Testament serait observée aussi dans le Nouveau» ${ }^{122}$. On notera ici la façon dont la conception des rapports entre ancienne et nouvelle Loi entre dans la résolution de questions cruciales sur la nature et l'étendue du pouvoir normatif de l'Église et sur l'autorité de ses normes. L'obligation déterminée de la dîme quitte le registre cérémoniel de la Loi pour entrer dans le droit de l'Église. L'institution par l'Église en renouvelle radicalement le sens: l'autorité de la norme chrétienne ne procède pas du précepte ancien, qui ne liait pas l'Église; la «consonance» avec la taxation vétérotestamentaire est un élément formel de la création normative de l'Église, qui participe néanmoins très clairement du rapport de continuité dialectique entretenu avec l'Ancien Testament.

L'opinion théologique commune s'oppose en l'occurrence aux positions vigoureuses d'Hostiensis, souvent adoptées par le théologien Gérard d'Abbeville. Le grand décrétaliste avait affirmé dans sa Summa aurea (achevée vers 1253) qu'il fallait «acquitter les dîmes sur toutes choses, intégralement et en vertu d'un précepte (ex precepto), même si certains maîtres veulent comprendre et exposer ces autorités autrement ${ }^{123}$. Les autorités sur lesquelles il se fondait, issues «tant de l'Ancien que du Nouveau Testament», incluaient la citation de l'Évangile de Matthieu $(23,23)$ à laquelle les

120. John Peckham, Quodlibet IV, 50, éd. Girard J. Etzkorn et Ferdinand Delorme, Grottaferrata, 1989, p. 289.

121. Ibidem.

122. Thomas d'Aquin, Quodlibet II, 8, éd. cit., p. 226.

123. Hostiensis, Summa aurea, éd. Lyon, 1556, fol. 253va. 
théologiens déniaient très généralement la qualité de confirmation néotestamentaire du précepte de la dîme. Il concluait que la dîme ne relevait pas du jugement individuel, mais de la nécessité, parce qu'elle était due ex precepto, etiam quoad quotitatem ${ }^{124}$. Symétriquement, les théologiens pouvaient fonder sur le droit la résolution de certaines questions. Gérard d'Abbeville, dont les positions sont généralement inspirées du droit canon ou de l'opinion des canonistes ${ }^{125}$, justifiait ainsi que même les juifs dussent acquitter la dîme en s'appuyant explicitement sur la décrétale De terris du Liber extra, qui donnait une définition réelle, et non personnelle, des dîmes prédiales ${ }^{126}$. Sans mentionner explicitement la décrétale, Henri de Gand contestait le fait que les prêtres pussent recevoir quoi que ce fût « des juifs et des autres usuriers », qui ne possédaient rien qui ne leur vînt de l'usure, et qu'il fallait restituer. Si les maisons situées dans la paroisse étaient obligées de verser un revenu au prêtre - comme le soutenait l'un des arguments invoqués au cours de la dispute - il s'agissait d'une obligation réelle, au sens où elle ne contraignait le locataire qu'en raison de la maison. Aussi la nature des biens possédés par les juifs la rendait-elle vaine. En conséquence, soit les prêtres ne devaient pas permettre que des maisons fussent louées par des juifs dans leurs paroisses, soit ils devaient réclamer leurs droits aux propriétaires des maisons, ou recourir à la justice publique pour récupérer les maisons grevées de ces droits. Mais des juifs, ils ne pouvaient rien recevoir ${ }^{127}$. Le caractère usuraire des biens possédés par les juifs introduisait ainsi une exception casuistique par rapport à la norme fondée sur la définition réelle de la dîme.

Des divergences théologiques apparaissent également à propos des cas de disjonction entre paroisse de réception des sacrements et paroisse d'exploitation agricole. Ces divergences font écho aux incertitudes même du droit canonique. Insérée au Liber extra, la

124. Ibidem.

125. Je me permets de renvoyer à Elsa Marmursztejn, «Une contribution au débat scolastique sur la dîme au XIII ${ }^{\mathrm{e}}$ siècle: six questions quodlibétiques inédites de Gérard d'Abbeville», Archives d'histoire doctrinale et littéraire du Moyen Âge, 77 (2010), p. 107-156.

126. C'est-à-dire des dîmes portant sur les produits du sol et le croît des animaux. Cf. Gérard d'Abbeville, Quodlibet XVI, 9, éd. E. Marmursztejn dans «Une contribution au débat scolastique sur la dîme au XIII ${ }^{\mathrm{e}}$ siècle», loc. cit., p. 156.

127. Henri de Gand, Quodlibet XIII, 16, éd. Jos Decorte, Louvain, Leuven University Press, 1985, p. 203-204. 
décrétale d'Alexandre III consacrée à cette difficulté ne tranchait guère. Elle exprimait l'embarras causé par la «diversité» des autorités des Pères et renvoyait, dans le doute, à la coutume ${ }^{128}$. Mais Raymond de Peñafort et la glose ordinaire distinguaient entre dîmes personnelles, dues à l'église où l'on recevait les sacrements, et dîmes réelles, versées à la paroisse d'exploitation agricole, sauf certa consuetudo ${ }^{129}$. Dans le même ordre d'idée, les divergences suscitées par le cas des dîmes personnelles renvoient, parfois explicitement, aux divergences entre canonistes. Le théologien Roger Marston hésite ainsi, dans un Quodlibet de 1283, à affirmer que les médecins et les avocats doivent la dîme de leur salaire, et les maîtres celle de leur collecta, privilégiant l'opinion du canoniste Geoffroi de Trani - selon lequel ces dîmes relevaient du droit positif, que la «coutume locale approuvée» abrogeait - contre celle de Jean le Teutonique, qu'il cite nommément ${ }^{130}$. Raymond de Peñafort avait exprimé l'hésitation inverse, en disant redouter d'affirmer que si les dîmes personnelles relevaient d'un "précepte humain», «ceux qui ne les acquittaient pas étaient libérés de la faute par la coutume contraire», et se bornait au «conseil» de les verser ${ }^{131}$.

Sans entrer plus avant dans le détail de l'analyse, on notera que l'apport spécifique des théologiens aux discussions sur la dîme semble avoir consisté dans la construction d'une norme chrétienne de la dîme par la déconstruction du précepte vétérotestamentaire: pour justifier l'obligation indéterminée de la dîme, le fondement du droit naturel, identifié à la raison, est substitué à la Loi ; l'obligation déterminée de la dîme relève moins de la continuité de l'une à l'autre Loi que d'une institution par l'Église qui en renouvelle le sens. Au-delà des différences de positionnement des théologiens par rapport aux sources juridiques qu'ils exploitent largement, l'analyse des textes révèle la pénétration des théologiens sur un territoire occupé par les canonistes. Elle manifeste également

128. Liber extra, lib. 3, tit. 30, cap. 18, Corpus iuris canonici, éd. Emil Friedberg, t. 2, Leipzig, 1881, col. 562.

129. Raymond de Peñafort, Summa de paenitentia, lib. 1, tit. 15, cap. 9, éd. Xavier Ochoa et Aloisio Diez, 1976, col. 422; Gl. Diversae ad Extra, 3, 30, 18, v., éd. Turin, 1588, col. 1366.

130. Roger Marston, Quodlibet III, 20, éd. Girard J. Etzkorn, Ignatius C. Brady, Quodlibeta quatuor, Quaracchi, 1968, p. 349-351.

131. Raymond de Peñafort, Summa de paenitentia, lib. 1, tit. 15, cap. 13, éd. cit., col. 426. 
la spécificité de leurs solutions, élaborées à partir des lacunes ou des hésitations du droit et des divergences entre ses commentateurs.

Dernier maillon de la chaîne des interprètes d'un texte sacré conçu comme légal, les docteurs se présentent comme des agents secondaires de l'accomplissement de la Loi ancienne inauguré par le Christ, et de la détermination des normes d'une «loi de grâce» indéterminée. Le mouvement historique d'ensemble qui se dessine est donc celui d'une ascension - des particularia de l'Ancien Testament, adaptés aux capacités d'un «peuple puéril» et conformes aux exigences d'un enseignement progressif et différencié analogue à la pratique pédagogique des maîtres, vers les préceptes universels de la loi évangélique destinée à un «peuple adulte» -, puis d'une descente vers les normes particulières requises par le gouvernement de la société chrétienne. Comme le dit Henri de Gand à propos de la détermination par l'Église du jour consacré au culte divin, «ce qui est induit de façon singulière est mieux respecté que ce qui est proposé par un précepte général $»^{132}$. L'entreprise théologique de construction des normes chrétiennes est compliquée par la pérennité de certains préceptes vétérotestamentaires, comme ceux du sabbat ou de la dîme. Au-delà d'une simple exégèse spirituelle - laquelle fonde néanmoins la détermination d'un certain nombre de normes par l'Église -, les théologiens se sont livrés à une analyse de la structure même de ces préceptes. L'exégèse est appliquée à la partie cérémonielle, mobile, du précepte, dont la partie morale, permanente, est refondée sur le droit naturel identifié à la raison. L'observance littérale est ainsi abolie par l'interprétation spirituelle des cerimonialia; les moralia sont parachevés. Les lieux de production des normes chrétiennes concernant le repos dominical ou la dîme apparaissent ainsi comme des lieux de réactivation de la tension entre ancienne et nouvelle Loi, où s'élaborent des solutions qui confirment la relation dialectique, au principe même de la doctrine chrétienne, entre Ancien et Nouveau Testament. Située hors du Décalogue, l'obligation d'acquitter la dîme suscite une tension moins immédiate et moins vive avec l'Ancien Testament, mais une interaction forte entre la théologie et le droit canonique qui constitue, au XIII ${ }^{\mathrm{e}}$ siècle, le second aspect du rapport général entre la théologie chrétienne et le droit.

elsa.marmursztejn@free.fr

132. Henri de Gand, Quodlibet 1, 41, éd. cit., p. 231. 